\title{
Movimentos de Espinosa e(m) Pêcheux
}

\author{
Espinosa's movements in Pêcheux
}

\author{
Denise Viuniski da Nova Cruz \\ Mestre em Educação pela UNIVALI, SC. \\ Professora de Clínica Médica e Semiologia Médica no Curso de Medicina, UNIVALI, SC \\ E-mail: novacruz@novacruz.med.br \\ Lucília Maria Sousa Romão \\ Livre-docente em Ciência da Informação pela FFCLRP/USP \\ Professora do curso de Ciências da Informação e Documentação da FFCLRP/USP \\ E-mail: luciliamsr@ffclrp.usp.br
}

\begin{abstract}
Resumo
O objetivo deste trabalho é revis[it]ar a trajetória da Análise do Discurso francesa, tomando como ponto de partida (e de chegada) a citação explícita à Espinosa na comunicação proferida no México, em novembro de 1977, por Michel Pêcheux durante o simpósio: $O$ discurso político: teorias e análises. Tendo como pano de fundo as provocações e as observações instigantes de Pêcheux na comunicação intitulada Remontemos de Foucault a Spinoza, busca-se marcar as contribuições filosóficas de Espinosa à teoria do discurso, especialmente na conceituação das heterogeneidades, bem como salientar as diferentes concepções do termo ideologia produzem efeitos na formalização de Michel Pêcheux sobre a noção de interpelação.
\end{abstract}

Palavras-chave: discurso, Espinosa, Pêcheux.

\begin{abstract}
This paper aims to review [re-visit] the trajectory of French Discourse Analysis, taking as its point of departure (and arrival) the explicit citation about Espinosa made in Mexico in November 1977, by Michel Pêcheux during the symposium: The discourse policy: theory and analysis. Having as background Pecheux instigating provocations and remarks, during his speech entitled Remontons de Foucault à Spinoza we seek to rescue philosophical contributions of Spinoza's theory of discourse, especially in conceptualization of heterogeneities, as well as highlight the different understandings of ideology in the discourse according to the two most important theoretical for this area of knowledge: Michel Foucault and Michel Pêcheux.
\end{abstract}

Keywords: discourse, Espinosa, Pêcheux

\section{Introdução}

O intento desse trabalho é formalizar, tanto quanto possível, um diálogo de Michel Pêcheux, teórico fundador da Análise do Discurso de filiação francesa, com Espinosa, marcando as aproximações e distanciamentos em relação ao conceito de ideologia e investigando os desdobramentos do texto "Remontemos de Foucault a Spinoza", escrito e proferido por Pêcheux em 1977. Para tal, faremos um percurso nos seguintes termos: i. reflexão sobre a trajetória teórica e conceitual de Pêcheux; ii. aproximação com o pensamento de Spinoza; iii. síntese para o campo discursivo. Com isso, pretende-se percorrer uma trilha

InCID: R. Ci. Inf. e Doc., Ribeirão Preto, v. 2, n. 1, p. 31-46, jan./jun. 2011. 
conceitual sem um objeto de análise específico, mas marcada pelo desejo de rastrear a trama de imbricamentos que sustenta diálogos na teoria.

Cabe salientar que Espinosa não se dedicou, especificamente, aos estudos da linguagem: "Não há uma teoria desenvolvida da linguagem no sistema de Espinosa. A linguagem não é um problema que Espinosa tenha selecionado como merecedor de ser pensado" (POMBO, 2010); entretanto - como vamos demonstrar neste artigo - a sua maneira singular de fazer filosofia contribuiu de forma marcada às possibilidades de encarar a língua em suas singularidades discursivas.

\section{Desmontando Michel Pêcheux}

Para compreender a relevância do que Michel Pêcheux afirmou em Remontemos de Foucault a Spinoza, faz-se necessária a análise das condições de produção deste seu "discurso", tanto para aproveitar as contribuições filosóficas de Espinosa, quanto para compreender as provocações de Pêcheux aos marxistas reformistas e a polêmica levantada dentro da área. Assim, é necessário visitar a posição em que se encontrava a teoria da Análise do Discurso (doravante AD) naquele momento histórico específico, visto que o referido texto permanece como estandarte de uma teorização específica, em um momento histórico e social definido e como um exemplo de como certos conceitos necessitaram ser construídos para, efetivamente, deslocar o pensamento e provocar movimentos absolutos nas diferentes áreas do conhecimento. Mesmo que mais tarde estes mesmos conceitos necessitem ser reformulados, desconstruídos e reconstruídos em um movimento que é apanágio do objeto mesmo de sua análise: o discurso.

Um dos aspectos mais relevantes da $\mathrm{AD}$ é a sua propriedade de fazer pesquisa, objetivando uma compreensão profunda do seu objeto de análise, o discurso, compondo o arsenal teórico que embasa o processo a par e passo com a análise em si. E assim, justamente, a teoria do discurso e a prática da análise do discurso da escola francesa foram sendo construídas nos movimentos - arrancos criativos, retrocessos e retomadas conceituais - que marcaram a trajetória acadêmica de Michel Pêcheux, seu principal teórico e expoente. É nesta trajetória que é possível visitar o processo de criação dos conceitos (teóricos) e dos procedimentos (práticos / de análise), considerando que os movimentos do autor representam o próprio dis-curso que, como lembra Orlandi (2010, p. 15), traz em sua etimologia "a idéia 
de curso, de percurso, de correr por, de movimento". Acompanhando Michel Pêcheux em sua vida acadêmica, observamos a complexa trajetória de uma teoria ocupada em compreender o sujeito em sua relação com a história, encontrando na linguagem a presença indelével da ideologia e do inconsciente que permeiam esta relação do sujeito com o mundo. "Sujeito como posição no discurso, afetado por um processo de interpelação ideológica que sinaliza quais e como os sentidos podem ser ditos" (ROMÃO, 2009, p.3)

A título de passagem, julgamos importante marcar que Michel Pêcheux nasceu em 1938 e, aos 25 anos, em 1963, recebeu o diploma de filósofo pela Ecole Normale Supérieur de Paris (ENS). A ENS, em todo seu prestígio, promovia na década de 60 encontros multidisciplinares e era, desde 1948, local de trabalho do grande mentor de Pêcheux, Louis Althusser; o encontro entre professor e aluno foi definitivo para a conceituação teórica construída nos anos seguintes. Outro encontro decisivo que se deu na ENS foi com a psicanálise, lembrando que Jacques Lacan faria seminários na Escola durante os anos de 1965 e 1966, mantendo a interlocução com vários intelectuais e artistas. Diversos pensadores aí se reuniam, atraídos pelas idéias que pululavam neste momento questionador da filosofia, das ciências humanas e sociais identificando na materialidade da linguagem, o discurso e a relação do homem com o mundo, indubitavelmente, atravessados pela ideologia e condicionados aos complexos mecanismos do inconsciente.

Em 1969, por influência de outro pensador ilustre da ENS, Georges Canguilhem médico e filósofo que tanto marcou o pensamento de Michel Foucault - Pêcheux inicia suas atividades no CNRS (Centre National de la Recherche Scientifique) onde encontra o psicólogo Michel Plon e o matemático-lingüista Paul Henry, organizando, em 1976, o chamado Seminário HPP interessado em "pesquisas sobre a teoria das ideologias". Maldidier (2003), renomada autora da análise do discurso, que havia já contribuído em 1969 nos textos do primeiro livro de Pêcheux - "Análise Automática do Discurso" -escreveu uma "história" dessas articulações, dividindo a trajetória da teoria do discurso em três fases distintas, a saber: a) o tempo das grandes construções; b) tentativas e c) a desconstrução domesticada.

Em relação ao primeiro tempo, ela destaca que a primeira publicação em livro a respeito desta nova área do conhecimento foi Análise Automática do Discurso e, embora considerada um esboço da teoria que se configurava, e, ainda, apesar de todas as críticas, correções e remodelações sofridas no futuro, a teorização estava em parte embrionária ali. A expressão AAD-69, como lembra a autora será sempre considerada o "pólo original”, o 
"protótipo" "quase mítico" da futura teoria do discurso (MALDIDIER, 2003, p. 19). Havia, após Maio de 68 - e uma vez reconhecidos um novo objeto de pesquisa e uma nova área de pesquisa - uma urgência teórica e de conceitos, mesmo que provisórios, para sacudir as ciências humanas e sociais da época. E isso se unia a uma certa fascinação de Pêcheux em relação a máquinas e a possibilidades que a tecnologia e a informática prenunciavam nas pesquisas de uma forma geral e mais especificamente nos objetos da Psicologia Social. Pêcheux e seus colaboradores pensavam uma "máquina discursiva", que fosse além das variáveis estruturalistas utilizadas pela análise de conteúdo; como alternativa às contagens de frequiência, a idéia era "arrancar a leitura da subjetividade” (MALDIDIER, 2003, p. 21).

A partir da AAD-69 e consolidada em 1975 com a publicação de Semântica e Discurso, a AD trabalha no espaço de confluência entre a Lingüística, o Marxismo e a Psicanálise, um campo de entremeio em que se funda um referencial teórico metodológico que considera a língua e o sujeito atravessados pela instância da ideologia e do inconsciente. Saussure está mais presente nos trabalhos iniciais, sendo que a "Tríplice Entente", como Pêcheux ironicamente se refere aos "seus" teóricos, só se mostrará completa - com Marx e Freud - mais tarde no percurso teórico. Lembrando que ao considerar Marx, Pêcheux inclui Engels e Lênin e ao trazer Freud inclui, certamente, a continuidade de seu trabalho através de Lacan. A grande contribuição lingüística da AAD foi a reformulação da teoria saussureana, dando vida ao conceito de discurso, que rompe com a dicotomia língua/fala e considera o processo de produção do discurso, agora denominado processo discursivo. Ao lado da construção dos conceitos teóricos são apresentados os procedimentos que, ao filtrar o objeto constituindo um corpus -, permitem identificar seqüências discursivas passíveis de análise. A construção da teoria e de seu dispositivo prático de trabalho contém o pressuposto de que as condições de produção do discurso materializam-se em uma estrutura específica a este processo e que a $\mathrm{AD}$ permite escutar, flagrando as formas de subjetivação e a interpelação ideológica que assujeitam o indivíduo e determinam a produção de sentido.

Ao se aproximar da informática, Pêcheux vê-se envolvido, definitivamente com a lingüística e com diversos lingüistas colaboradores. Em 1971, em um número especial da revista Langages, editado por Julia Kristeva, ele, Gadett e Henry publicam La sémantique et la coupure saussurienne : langue, langage, discours, um estudo crítico, um corte na teoria estruturalista de Saussure, afirmando a teoria do discurso como um novo tipo de estruturalismo, ou seja, aquele preocupado com as relações políticas e sociais que tratam de responder a questão "o que pode a lingüística quando se trata do sentido?" (MALDIDIER, 
2003, p. 29). Propõem no lugar da semântica saussuriana uma "semântica discursiva", que deixa clara uma posição de que o discurso é um construto teórico feito a partir da fala saussuriana; assim, ficam a sistematicidade e a estrutura, saem o formalismo duro e o subjetivismo. Afigura-se a nova força da semântica discursiva: o sentido ultrapassa a lingüística, está sempre em jogo, é movediço e não passível de aprisionamento; ele escapa às regras e às tentativas de contenção, o que convida o analista a uma escuta sempre aberta aos poros da significação.

Em 1971, somente dois anos após o esboço da AAD, a teoria do discurso já incluía a noção de que certas formações ideológicas comportam formações discursivas em um processo pelo qual o que é dito é aquilo que pode e deve ser dito a partir de uma posição dada e em uma definida conjuntura histórica e social. Neste contexto, para Pêcheux, formação discursiva é um recorte ou uma regionalização do que será chamado mais tarde de interdiscurso; ou seja, a formação discursiva determina o que pode (pôde) e deve ser dito (ou deve ter sido dito desta forma, deste lugar, nestas condições de produção). O discurso terá (este ou aquele) sentido porque se coloca dentro de uma formação discursiva específica.

Apesar de não ter sido citado, diretamente, no artigo da Langages de 1971, são as afirmações de Althusser em Ideologias e Aparelhos Ideológicos que sustentam as novas práticas das ciências sociais e também o olhar de Pêcheux. É a partir da afirmação de Althusser: "A ideologia interpela indivíduos em sujeitos" (ALHUSSER, 1974) que Pêcheux, nas palavras de Maldidier "racha de alto a baixo" tudo o que poderia fazer do sujeito o centro do processo de enunciar, falar, escrever, ler e mais radicalmente de dar sentido à realidade; é com isso que Pêcheux se encaminha para postular uma teoria materialista do discurso. Há, no conceito pêcheutiano de formação discursiva o "filtro" marxista althusseriano o que determina, nesta ótica, “a não-autonomia das práticas discursivas” (GRANGEIRO, 2011).

[...] uma formação discursiva não é um espaço estrutural fechado, pois é 'invadida'
por elementos que vêm de outro lugar (isto é, de outras formações discursivas) que
se repetem nela, fornecendo-lhe suas evidências discursivas fundamentais (por
exemplo, sob forma de "pre-construídos" e de "discursos transversos"). É essa
"invasão" de outros discursos - pré-construídos e transversos - que leva ao
interdiscurso, à memória do dizer, tão importante para a interpretação da memória
política (PÊCHEUX, 1990, p.314)

Ao lado de Paul Henry e embasado na lógica de Frege, Pêcheux procura no funcionamento da língua as relações sintáticas e semânticas que revelam "traços de construções anteriores", ou o "pre-construído" que embasam a teorização do interdiscurso como aparecerá em Semântica e Discurso, o grande livro de Michel Pêcheux (PÊCHEUX, 
1990, p. 34) sobre o qual falamos a partir de agora. O lançamento dessa obra, em maio de 1975, é precedido pela publicação de um artigo na revista Langages que já apontava a articulação da lingüística, recuperando os mecanismos sintáticos e avançando nos processos de produção do discurso; do marxismo com a teoria da ideologia; e da subjetividade com as implicações da psicanálise na construção da teoria da enunciação. Através da análise dos domínios semânticos e das famílias parafrásticas, o autor procura as chamadas "matrizes do sentido" e teoriza que existe uma ilusão que faz o sujeito pensar que está "na fonte do sentido". Para explicar esta ilusão, aparecem os conceitos dos dois esquecimentos que darão conta de explicitar os procedimentos pelos quais a enunciação e a formulação do discurso assumem a aparência de original e sujeitos de si.

Assim, o esquecimento número dois (da ordem da enunciação) é aquele que faz parecer que o que foi dito somente poderia sê-lo com aquelas palavras; causa a impressão da realidade do que pensamos: "ilusão referencial". É semi-consciente, de forma que às vezes se recorre às famílias parafrásticas para esclarecer o que se quer dizer (ORLANDI, 2010, p.35), o que fisga o sujeito na ilusão de uma relação termo a termo entre a linguagem e a realidade. O esquecimento número um é o dito "esquecimento ideológico", da ordem do inconsciente, inacessível ao sujeito. Traz a ilusão de que o sujeito é a origem do que está sendo dito e que as palavras começam nele mesmo, o que o faria a fonte dos sentidos que produz. Tais esquecimentos são necessários para a constituição do sujeito e atravessam todo o processo de dizer, independente da sua "vontade" ou livre escolha. Ao propor isso, Pêcheux inaugura reflexões sobre o sujeito do discurso, não categorizável e passível de outra abordagem que não aquela destinada pelo empirismo, desmontando certezas e fazendo falar o cerne de sua teoria. Assim, o sujeito é posição na linguagem, permanentemente situado a partir da formação discursiva a qual se filia, capturado pelos esquecimentos e interpelado pela ideologia como mecanismo de naturalização de sentidos.

\section{As tentativas tentadoras: o sonho mais doce}

A comunicação de Michel Pêcheux no México, intitulada Remontemos de Foucault a Espinosa data do ano de 1977 e é considerada uma crítica dirigida diretamente aos marxistas reformistas que pensam os caminhos da $\mathrm{AD}$ a partir de um ponto de vista da sociolingüística (MALDIDIER, 2003, p. 62-65). O tom de verdade e provocação assumido por Pêcheux dá a entender sua contrariedade direta em relação a Michel Foucault, que também teorizava "a 
produção do discurso ao mesmo tempo controlada, selecionada, organizada e redistribuída por certo número de procedimentos que têm por função conjurar seus poderes e perigos, dominar seu acontecimento aleatório, esquivar sua pesada e temível materialidade". (FOUCAULT, 2009, p. 9). O autor de A ordem do discurso e de A Arqueologia do saber procurava as dispersões e as regularidades na linguagem, as séries regulares e distintas de acontecimentos que poderiam explicar a emergência de um determinado discurso: "É para estabelecer as séries diversas, entrecruzadas, divergentes muitas vezes, mas não autômatas, que permitem circunscrever "o lugar" do acontecimento, as margens de sua contingência, as condições de sua aparição" (FOUCAULT, 2009, p. 56). Mas então, por que tamanha contrariedade nesta comunicação de Pêcheux e por que recorrer a Espinosa, filósofo do século XVII, para enfatizar esta crítica? Acompanhemos Remontemos, junto com Pêcheux (1977) ${ }^{1}$.

Nesse trabalho, Pêcheux explica que os clássicos do marxismo - Marx e Lênin - não teorizaram a relação da ideologia com a língua ou com o discurso tendo deixado esta tarefa para os "universitários progressistas": alguns lingüistas, historiadores e filósofos. Pêcheux nomeia (incluindo-se) estes acadêmicos como fazendo parte de uma "escola francesa de análise do discurso". A questão inicialmente colocada e que permeia toda a provocação de Pêcheux é de que a prática acadêmica ou universitária estaria se afastando da prática política, importante para os analistas do discurso de filiação marxista clássica como ele próprio. Ele acusa a universidade de "universalidade, no sentido de generalidade abstrata inutilizável" e tal formulação tem um caráter, também, de autocrítica, o que para nós cria o efeito de sentido de um questionamento do próprio Pêcheux sobre o fazer da Análise de Discurso no âmbito universitário, ou seja, uma vertiginosa inquietação diante de sua "própria matéria".

Pêcheux conclama os analistas de discurso a fazerem, além da prática de lingüistas e analistas de textos e de sentidos, política, dizendo: "uma certa maneira de tratar os textos está inextrincavelmente imbricada em uma certa maneira de fazer política”. Entretanto, ao reclamar que os acadêmicos da análise de discurso façam política em suas práticas, Pêcheux não fala de qualquer posição política. A questão de Michel Pêcheux neste momento é que há que se tomar posição na luta de classes "já que essa tomada de posição determina, na verdade, a maneira de conceber as formas materiais concretas sob as quais as "idéias" entram em luta na história".

\footnotetext{
${ }^{1}$ Todas as citações desta seção do texto são da tradução da professora Maria do Rosário Gregolin. Disponível em: <http://www.moodle.ufu.br/pluginfile.../P_CHEUXREMONTEMOS_1_1_.doc?>. Texto original publicado em MALDIDIER, D. L'ínquietude du discours. Paris: Cendres, 1990, p. 245-260.
}

InCID: R. Ci. Inf. e Doc., Ribeirão Preto, v. 2, n. 1, p. 31-46, jan./jun. 2011. 
O criador da teoria discursiva está submerso em plena luta de classes, o que faz falar a marxista clássica da contradição senhor/escravo; proprietário/assalariado; dominador/dominado. O que é "evidente para os militantes marxista-leninistas" não está claro na prática "dos especialistas da linguagem": estas são a provocação e a polêmica instauradas já que há possibilidade de se fazer $\mathrm{AD}$ apartada da contradição marxista e dos condicionamentos teóricos do materialismo histórico? Para Pêcheux, naquele momento, a resposta era não; e para argumentar neste sentido, o filósofo recorre a dois expedientes: a) criar uma tipologia das correntes dos estudos da linguagem e; b) resgatar Espinosa, traçando um paralelo de sua prática em relação aos discursos bíblicos (no Tratado Teológico Político) com os procedimentos de Michel Foucault na Arqueologia do Saber. Nesses termos, Pêcheux teoriza três correntes na teoria da linguagem;

a) Lógico-formalista: preocupada com as regras gramaticais e com os universais da língua. Traz a concepção filosófica de que a língua está apartada do tempo e da história sendo garantida pela estrutura conseqüente ao "ser e ao pensamento". Para Pêcheux, esta corrente retira, completamente, a história da sua relação com a linguagem que passa a ser vista como "uma teoria universal das idéias". A consequiência política, desta maneira de pensar a linguagem é que a luta ideológica de classes desaparece, fica sem sentido. Pêcheux vai mais longe, afirmando que esta corrente contém e expressa a "posição de classe da ideologia burguesa fundada sobre a eternidade antropológica jurídico-moral do triângulo sujeito-centro-sentido”. Que escolha de palavras! Diretas, rápidas e certeiras.

b) Corrente da mudança social na história incluindo os filologistas e os neogramáticos. Para estes teóricos as línguas são formadas, evoluem e se diferenciam e desaparecem como se fossem espécies vivas. Aqui, Pêcheux coloca os ditos sociolingüistas, alvo direto de suas criticas. A conseqüência política desta corrente "historicista" do pensamento é uma visão historicista, também, das lutas de classe. Algo que historicamente se constituiu e que, na história, será superado. Na maneira teórica de explicar, seria como se as heterogeneidades políticas (que para Pêcheux é o cerne da ideologia e da contradição marxista) ficam submetidas ou condicionadas às homogeneidades sociais que seriam historicamente contingentes. Nesta posição filosófica e linguística, Michel Pêcheux encontra a negação da luta de classes, acusando este "reformismo" de ter entendido a dominação como "forma de interiorização" e não como divisão política ideológica e presente sempre (passível de análise) no discurso. 
c) Tendência do risco da fala. Pêcheux delineia uma corrente de lingüistas "sofistas" ou dialógicos, na qual os sujeitos "se confrontam sobre o terreno da máscara e do jogo verbal". A consequiência prática desta corrente é a falta da autonomia filosófica e a perpetuação das questões históricas (e da luta de classes) num terreno dialógico e conflituoso, afirmando também a ideologia da classe burguesa, dominante.

Após propor estas três diferentes correntes da lingüística naquele momento, especificamente entre os analistas de discurso franceses, Pêcheux deixa seu recado provocador, polêmico e, principalmente instigante que transcrevemos abaixo por ser o cerne da comparação teórica que fará a seguir, entre Espinosa (político) e Foucault (universitário).

Trata-se de acentuar que essas posições filosóficas têm fortes ressonâncias concretas nos trabalhos lingüísticos de diversas correntes e de alertar politicamente àqueles que desejam diretamente "aplicar a lingüística" ao materialismo histórico a fím de estudar as ideologias e os discursos políticos: uma mudança de terreno se impõe, se quiser-se evitar que o universitário não se sobreponha (domine) o político.

\section{Comparando Espinosa e Foucault}

Pêcheux propõe um percurso teórico "em torno" do marxismo, interrogando "o trabalho das origens"; coloca lado a lado estes dois filósofos não-marxistas, mas não perdoa Foucault ao dizer que Espinosa não dispunha da teoria marxista no século XVII, enquanto que seu conterrâneo e contemporâneo não tem "desculpa" de evitar o marxismo em sua época. É com aspereza que diz: "ninguém pode ter impunemente um discurso paralelo ao materialismo histórico sem encontrá-lo no contrafluxo". Vejamos em que pontos Michel Pêcheux aproxima os dois filósofos.

a) Relação com a lingüística. Espinosa "interpreta os textos sagrados e determina as condições sob as quais eles foram, ou não, desviados de seu sentido primitivo [...] isto o conduz a distinguir língua e discurso". Espinosa afirma que a palavra se mantém, mas o sentido dos textos varia. Foucault também afirma esta possibilidade (transcrita literalmente por Pêcheux): "uma língua constitui sempre um sistema para enunciados possíveis - um conjunto finito de regras que autoriza um número infinito de desempenhos ${ }^{2,}$

b) Relações entre os enunciados. Explicitamente, Espinosa faz referências às metáforas quando exemplifica que Moisés se refere a "Deus é um fogo", deixando claro o sentido de

\footnotetext{
${ }^{2}$ As citações de Foucault, usadas por Pêcheux, são todas da Arqueologia do Saber.
}

InCID: R. Ci. Inf. e Doc., Ribeirão Preto, v. 2, n. 1, p. 31-46, jan./jun. 2011. 
"Deus é invejoso" localizando o enunciado fogo como metáfora para "cólera" e "ciúmes, inveja". Foucault também aponta esta relação entre os enunciados se propondo a pesquisar a ordem sucessiva do aparecimento de enunciados, as correlações passíveis de verificação simultânea, além de funcionamento recíproco (uma coisa dita em lugar da outra, reciprocamente), considerando ainda as transformações possíveis do enunciado ao significar o mesmo ou seu contrário. Trata-se aqui das "formas de repartição" e dos "sistemas de dispersão" foucaultianos.

c) Lugar no discurso. Espinosa afirma que há que se determinar o autor e as condições de produção (circunstâncias) de textos para que se possa compreender o sentido do que é dito. Da mesma forma, sabemos, Foucault enfatiza as condições do discurso do ponto de vista de quem fala.

d) Regime de materialidade do imaginário. Aqui as diferenças aparecem e as questões da ideologia em Espinosa e em Foucault se tornam prementes para Michel Pêcheux. Espinosa explica que "narrativas muito semelhantes podem aparecer em livros diferente, sob formas desfiguradas e irreconhecíveis". Espinosa falava de Deus, e Deus como nos lembra Pêcheux "não tem estilo próprio". Para exemplificar a maneira como Foucault trabalha o regime do imaginário, Pêcheux o acusa de estar "um pouco bloqueado" justamente onde Espinosa avança!

É interessante a distância tomada neste momento de Pêcheux em relação à utilização da categoria da contradição por Foucault. Por mais que tenha se afastado dos clássicos do marxismo, Foucault sempre manteve a contradição (ainda que não centrada na luta de classes) no cerne de seu arsenal "arqueológico":

O discurso é o caminho de uma contradição a outra: se dá lugar às que vemos, é que
obedecem à que oculta. Analisar o discurso é fazer com que desapareçam e
reapareçam as contradições, é mostrar o jogo que nele elas desempenham; é
manifestar como ele pode exprimi-las, dar-lhes corpo, ou emprestar-lhes uma
fugidia aparência (FOUCAULT, 2005, p. 171).

Os comentários de Pêcheux, agudos e fortes se prestam muito bem à Espinosa porque, como apontado por Gilles Deleuze em seus cursos sobre este pensador, proferido em Vincennes em Novembro de 1980, Espinosa foi capaz de se servir de Deus para "liberar o conceito" (DELEUZE, 2009, p.59). Espinosa escava um novo Deus - o próprio ateísmo (para Pêcheux) - de dentro do discurso dos textos mais sagrados da religião. Façamos uma pausa para aproveitar Espinosa em seu devir-analista-de-discurso. 


\section{Montando Espinosa}

O nome do filósofo, por si, já é motivo de análise. Nascido Bento (em português) e batizado na sinagoga como Baruch (em hebraico), filho de uma família de prósperos comerciantes judeus de origem portuguesa que se exilaram em Amsterdã no final do século XVI em busca de liberdade de religião. Inicia-se muito jovem nos estudos da bíblia (Talmud) e da filosofia, estuda especialmente as idéias cartesianas em voga na rica Holanda do século XVII. Aos 24 anos, por suas idéias em relação à religião, a Deus, à alma e ao corpo, Espinosa foi excomungado da religião judaica em um processo violento e ameaçador (herem em hebraico) formalmente registrado pelos rabinos da sinagoga de Amsterdã. A partir de então, o filósofo assume seu nome em Latim e escolhe esta língua (nova para ele) para escrever filosofia. A partir de então, Espinosa passa a assinar Benedictus de Spinoza ${ }^{3}$.

Ao invés de reclamar abrigo ou reconciliação dentro da religião judaica ou católica ou protestante, Espinosa publica, em 1670, aos 37 anos de idade, o único livro que viu ser lido publicamente em vida: O Tratado teológico-político texto comentado por Michel Pêcheux em Remontemos. A epígrafe deste texto deixa clara a intenção de afirmar que a liberdade de pensamento pode viver ao lado da paz, mas que não pode haver paz se a mesma for suprimida (ESPINOSA, 2008, prefácio). Para Deleuze (2002, p. 15-16) as principais interrogações do Tratado são: a) "por que o povo é profundamente irracional?"; b) "Por que os homens lutam "por" sua escravidão como se fosse sua liberdade?"; c) "por que é tão difícil não apenas conquistar mas suportar a liberdade?"; d) "por que uma religião que reivindica o amor e a alegria inspira a guerra, a intolerância, a malevolência, o ódio, a tristeza e o remorso?

Não é de estranhar que a publicação deste livro tenha suscitado como poucos, insultos, interdições, críticas e proibições. "Em 1674, os pastores protestantes exigiram que ele fosse condenado pelos cristãos" (CHAUÍ, 2005, p. 10). As exigências foram tão insistentes, que mesmo na Holanda de Guilherme de Orange, foi promulgado um édito proibindo a impressão e a divulgação do Tratado! Mas o que disse Espinosa no Tratado - e mais tarde de forma didática e emocionada na sua obra mais emocionada: Ética - que provocou tanta revolta no mundo moderno? Basicamente:

a) Conceituou Deus como sive Natura, Deus e a Natureza são a mesma coisa;

\footnotetext{
${ }^{3}$ Preferimos neste texto, Espinosa, em português. Talvez para nos sentirmos mais próximos do filósofo, também para seguir a orientação da autora brasileira mais conhecedora da obra de Espinosa: Marilena Chaú. Lembramos que na tradução para o português de Tomaz Tadeu da Ética é usada a grafia Spinoza.
}

InCID: R. Ci. Inf. e Doc., Ribeirão Preto, v. 2, n. 1, p. 31-46, jan./jun. 2011. 
b) Explicou que Deus é a Substância, causa de si mesma (causa sui) e que, portanto, é "aquilo cuja essência envolve a existência, ou seja, aquilo cuja natureza não pode ser concebida senão como existente" (SPINOZA, 2009, p. 13);

c) Retirou a liberdade de arbítrio tanto de Deus como dos homens numa lógica de argumentação filosófica que é tão simples quanto profunda, tão lógica quanto mágica. Nada em Deus - ou na Natureza - é contingente. De um só golpe Espinosa acaba com as noções de pecado e perdão, de superstição religiosa, de intermediação religiosa entre homens e Deus, de Bem e de Mal. De um só golpe Espinosa acaba com qualquer vestígio de transcendência e instaura o "mais radical dos planos de imanência" ${ }^{\text {; }}$.

d) Demonstrou que Deus não é "antropocentrado" e muito menos antropomórfico. A Substância contém infinitos atributos dos quais conhecemos a Extensão (corpo) e o Pensamento. Ainda mais radical e importante: o corpo e o pensamento (a alma) estão em isonomia, isto é, a mente processa aquilo que o corpo percebe. Deus e Natureza; Corpo e Alma, uma coisa só ${ }^{5}$. Fim às dicotomias da modernidade, mudança radical ao pensamento de Descartes que naquele exato momento estava consolidando a noção de corpo-máquina subordinado pela mente que pensa;

e) Argumentou que a política não nasce do contrato social de partes individuais, mas do desejo coletivo de muitos (multitudo), devolvendo o poder político ao sujeito-político, retirando de vez o poder das mãos de teólogos e religiosos que para Espinosa compõem, junto com os tiranos e os escravos a tríade dos espíritos tristes!;

Horrorizados, os "espíritos tristes" proibiram a leitura de Espinosa. Deus sive Natura significa um Deus contingente, sem ouvidos às necessidades e iniqüidades humanas. Sem livre arbítrio os homens ficariam sem responsabilidades (e sem dívidas morais, sem pecados ou temores ou superstições). "Espinosa surgia como precursor da verdadeira racionalidade moderna" (CHAUÍ, 2005, p.12).

Pois é trazendo Espinosa que Michel Pêcheux reclama de Foucault uma utilização política de sua teoria. Assim como Espinosa utilizou a análise dos textos sagrados no

\footnotetext{
4 “[Espinosa] mostrou, erigiu, pensou o “"melhor” plano de imanência, isto é o mais puro, aquele que não se dá ao transcendente, nem propicia o transcendente, aquele que inspira menos ilusões, maus sentimentos e percepções errôneas...” (DELEUZE e GUATTARI, 1997, p.79)

5 "A ordem e a conexão das idéias é a mesma que a ordem e a conexão das coisas" (Proposição VII, Livro II, Ética: Spinoza, 2009)
}

InCID: R. Ci. Inf. e Doc., Ribeirão Preto, v. 2, n. 1, p. 31-46, jan./jun. 2011. 
Tratado, para libertar de dentro da religião, o conceito de Deus ${ }^{6}$, Pêcheux cobra a necessidade de analisar o discurso e encontrar dentro do próprio discurso (religioso, ou político,) a categoria da contradição marxista e o posicionamento teórico, prático e político da luta de classes. Para entender a analogia que Pêcheux faz do trabalho filosófico-político de Espinosa com a análise de discurso e com contradição marxista da luta de classes que perpassa a ideologia de uma ótica althusseriana vejamos o que diz a nota introdutória da edição portuguesa do Tratado:

[...] porque Espinosa, como já alguém disse, se nos antecipou a ir espreitar por detrás do espelho, a indagar a natureza da imagem que qualquer sociedade tem de si própria e da sua lei ou ordem interna, concluindo que ela não é senão isso mesmo, ou seja, uma simples imagem que a perspectiva irremediavelmente particular de cada um e de cada povo tende a representar como espaço onde a transcendência irrompe soberana, de modo a que a potência do legislador se cubra de legitimidade inquestionável" (AURÉLIO, 2004, Nota).

A década de 1980 prenunciava uma renovação no pensamento teórico do grupo reunido ao redor de Michel Pêcheux. O tom de verdade universal e unificadora da teoria estabelecida nos anos anteriores estava se despedindo. Substituindo o conceito de discurso aparecia o de materialidades discursivas. Falava-se de uma passagem da unidade para a multiplicidade. A análise do discurso se abria e se colocava entre as outras disciplinas que tratavam destas materialidades. Outro encontro se faz notar na trajetória de Pêcheux: JeanMarie Marandin que conhecia muito bem a teoria de pêuchetiana sendo, portanto, capaz de aproximá-la a outras referências lingüísticas e filosóficas - a Arqueologia de Foucault e a Filosofia da diferença de Gilles Deleuze (MALDIDIER, 2003, p. 72).

Os caminhos da AD se aproximavam da relevância de considerar o interdiscurso em sua relação com o intradiscurso, abrindo mão dos "filtros" impostos anteriormente. A discursividade se aproximava da singularidade do acontecimento. Outro encontro, ou reencontro, extremamente importante para Pêcheux - e para o futuro da análise do discurso foi com Jacqueline Authier que formularia os conceitos de heterogeneidade mostrada e constitutiva que permitiram vislumbrar o jogo entre interdiscurso (eixo vertical/ dimensão histórica) e intradiscurso (eixo horizontal / seqüenciamento) nos procedimentos de análise. Por fim, um último encontro importante do grupo de trabalho de Michel Pêuchex foi com as disciplinas afins ao discurso, especialmente a História (Jacques Guilhaumou), a psicologia, a leitura de arquivo e a sociologia. "A análise de discurso devia sair de seu fechamento , se confrontar com outras disciplinas, "por-se à prova"” (MALDIDIER, 2003, p. 80). No seu

\footnotetext{
6 "Através do conceito filosófico de Deus, se faz, - e isso somente se faz nesse nível -, se faz a mais estranha criação da filosofia como sistemas de conceitos” (DELEUZE, 2009, p. 60)
}

InCID: R. Ci. Inf. e Doc., Ribeirão Preto, v. 2, n. 1, p. 31-46, jan./jun. 2011. 
último texto $O$ Discurso: estrutura ou aconteciment, conferência feita em Inglês, nos Estados Unidos em Julho de 1983, pouco tempo antes de sua morte, Michel Pêcheux reconhece que a teoria do discurso havia levado a reflexão sobre a materialidade do sentido ao extremo. Nas palavras de Maldidier (2003, p.96):

De uma ponta à outra, o que ele teorizou sob o nome de "discurso" é o apelo de algumas idéias tão simples quanto insuportáveis: o sujeito não é fonte do sentido; o sentido se forma na história através do trabalho da memória, a incessante retomada do já-dito; o sentido pode ser cercado, ele escapa sempre.

Bastava agora, abrir a estrutura para o acontecimento, abrir a análise do discurso às outras disciplinas; puxar o fio das discursividades no jogo das heterogeneidades e do cruzamento do inter com o intradiscurso (PÊCHEUX, 2008). Michel Pêcheux fundou a análise de discurso e a teoria do discurso e legou um arsenal teórico e de procedimentos que, nas materialidades da linguagem, permitem a compreensão das relações históricas entre os indivíduos e a sociedade.

\section{Remontando de Espinosa a Michel Pêcheux}

A tarefa da AD foi semeada por Michel Pêcheux para ter continuidade na voz de seus colaboradores, colegas, alunos e seguidores. A (des)construção dos pressupostos teóricos que já vinha em curso no início dos anos de 1980 e a (re)construção dos dispositivos de análise seguiram em direção a uma teoria que se comunica com as diversas disciplinas das ciências humanas e sociais mantendo o essencial da teorização fundamental de Michel Pêcheux. A discussão em torno de Remontemos e os questionamentos levantados naquela ocasião por Michel Pêcheux são tão atuais que Jacques Guillaumou (que estava presente no Seminário do México em 1977) e Francine Mazière, ambos colaboradores importantes na trajetória da análise de discurso francesa publicam agora, na revista SEMEN um artigo justamente discutindo a necessidade de retomar os conceitos de ideologia frente aos novos acontecimentos que perpassam o discurso da atualidade (GUILLAUMOU e MAZIÈRE, 2010).

No Brasil, os estudos e as pesquisas de Orlandi, dentre outros pesquisadores, são um exemplo vivo de como a teoria de Pêcheux se configurou em um horizonte de procedimentos que mantendo os pressupostos teóricos da análise do discurso, cria um dispositivo analítico, individualizado para cada análise específica, de acordo com a materialidade estudada e com a finalidade de compreender o sentido e a realidade (ORLANDI apud MALDIDIER, 2003). 
Para cada questão de análise busca-se um arsenal teórico que possa dar conta da compreensão da memória discursiva, da ideologia, dos mecanismos conscientes e inconscientes envolvidos que desembocam na formulação e na enunciação de um discurso específico (objeto simbólico / de análise). O devir da trajetória de Michel Pêcheux e da análise de discurso da escola francesa pode ser bem compreendido nos seguintes termos:

[...] se a Análise do Discurso é herdeira das três regiões de conhecimento -
Psicanálise, Lingüística, Marxismo - não o é de modo servil e trabalha uma noção -
a de discurso - que não se reduz ao objeto da Lingüística, nem se deixa absorver
pela Teoria Marxista e tampouco corresponde ao que teoriza a Psicanálise. Interroga
a Lingüística pela historicidade que ela deixa de lado, questiona o Materialismo
perguntando pelo simbólico e se demarca da Psicanálise pelo modo como,
considerando a historicidade, trabalha a ideologia como materialmente relacionada
ao inconsciente sem ser absorvida por ele. (ORLANDI, 2010, p. 20)

A admoestação de Michel Pêcheux em Remontemos reclama, mais que tudo, uma preocupação política e prática dos acadêmicos universitários envolvidos com a análise do discurso. Ainda muito preso ao sonho mais doce de sua geração, Pêcheux cobrava o posicionamento político de seus colegas dentro da contradição marxista da luta de classe. Talvez, Espinosa pudesse ter lhe dado tranqüilidade e rumo, uma vez que para este filósofo, mais do que política - no sentido explícito - trata-se de conhecer as coisas por suas causas e efeitos, cada vez mais próximas da compreensão de que tudo - as coisas e os seres - são diferentes modos de expressão dos atributos da Substância: diferença e heterogeneidades puras. Como diz Deleuze (2002, p.127): "Então, estar no meio de Espinosa... implica um modo de vida, uma maneira de viver". É a maneira espinosista de ultrapassar a política e chegar na ética e, pela vida do discurso, é também o modo de chegar à instância do político no funcionamento da linguagem.

\section{Referências}

ALTHUSSER, L. Aparelhos ideológicos do estado. Lisboa: Presença, 1974.

AURÉLIO, D. P. Nota à presente edicção. In: ESPINOSA, B. Tratado teológico-político. Lisboa: Impresnsa Nacional-Casa da Moeda, 2004.

CHAUÍ, M. Espinosa: uma filosofia da liberdade. São Paulo: Moderna, 2005.

DAMÁSIO, A. Em busca de Espinosa: prazer e dor na ciência dos sentimentos. São Paulo: Companhia das Letras, 2003.

DELEUZE, G. Espinosa: filosofia prática. São Paulo: Escuta, 2002. 
Cursos sobre Spinoza: Vincennes, 1978-1981. Fortaleza: EDUECE, 2009.

; GUATTARI, F. O que é filosofia? São Paulo: Editora 34, 1997.

ESPINOSA, B. Tratado teológico-político. São Paulo: Martins Fones, 2008.

FOUCAULT, M. A ordem do discurso São Paulo: Loyola, 2009.

A arqueologia do saber. Rio de Janeiro: Forense Universitária, 2005.

GRANGEIRO, C. R. P. A propósito do conceito de formação discursiva em Michel Foucault e Michel Pêcheux. Disponível em: <http://www.discurso.ufrgs.br/sead2 /doc/claudiagrangeiro.pdf>. Acesso em: 06 mar. 2011.

GUILLAUMOU, J; MAZIÈRE, F. Ainsi, nous sommes qui nous sommes dans le Mississippi. Semen, v. 29, 2010.

MALDIDIER, D. A inquietação do discurso: (re)ler Michel Pêcheux hoje. Campinas: Pontes, 2003.

ORLANDI, E. P. Discurso e leitura. Campinas: Cortez: Ed. da UNICAMP, 2010.

O objeto de ciência também merece que se lute por ele. In: MALDIDIER, D. A Inquietação do discurso: (re) ler Michel Pêcheux hoje. Campinas: Pontes, 2003.

Análise do discurso: princípios \& procedimentos. São Paulo: Pontes, 2010.

PÊCHEUX, M. O Discurso: estrutura ou acontecimento. Campinas: Pontes, 2008.

Semântica e discurso. Campinas: UNICAMP, 1995.

Análise automática do discurso. In: GADET, F.; HAK, T. (Orgs.). Por uma análise automática do discurso. Campinas: Ed. da UNICAMP, 1990.

POMBO, O. Palavra e esplendor do mundo. Lisboa: Fim de Século, 2010.

ROMÃO, L. M. S. O discurso em Leitura de Barraco: sujeito e ideologia. In: SEAD Seminário de Estudos em Análise do Discurso, 1969-2009: memória e história na/da Análise do Discurso, 4., 2009. Caderno de resumos e programação, Porto Alegre, 2009. v. 1. p. 3940 .

SPINOZA, B. Ética. Belo Horizonte: Autêntica, 2009. 